\section{Multidisciplinary Severe Asthma Management: The Role of Hospital Pharmacists in Accredited Specialized Adult Asthma Units in Spain}

\author{
Villamañán $E^{1}$, Herrero $A^{1}$, Álvarez-Sala $\mathrm{R}^{2}$, Quirce $\mathrm{S}^{3}$

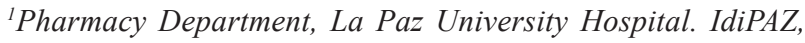 \\ Madrid, Spain \\ ${ }^{2}$ Pneumology Department, La Paz University Hospital, IdiPAZ, \\ Madrid, Spain \\ ${ }^{3}$ Allergy Department, La Paz University Hospital, IdiPAZ, Madrid, \\ Spain
}

J Investig Allergol Clin Immunol 2020; Vol. 30(4): 305-306 doi: 10.18176/jiaci.0488

Key words: Severe asthma. Hospital pharmacist. Multidisciplinary unit. Biologic therapy.

Palabras clave: Asma grave. Farmacéutico de hospital. Unidad multidisciplinar. Terapia biológica.

\section{To the Editor:}

Asthma is an inflammatory disorder that affects some 339 million people worldwide and generates a considerable economic impact [1]. Despite their efficacy, standard therapies very often do not manage to mitigate symptoms; consequently, finding new treatments is a permanent challenge. In severe asthma, the emergence of biological medications in the pharmaceutical market has enabled treatment to be personalized based on the predominant pathophysiological abnormality in the individual patient [2].

The complex management of patients with severe asthma necessitates follow-up in specialized units. In contrast with other countries, Spanish regulations for accreditation require these units to be multidisciplinary, that is, integrated by pulmonologists, allergists, nurses, and psychologists $[3,4]$, but not pharmacists. The involvement of pharmacists in the care of chronically ill patients, such as patients with severe asthma, has already proven advantageous in other diseases by improving clinical outcomes and the safety and efficacy profile of medication [5]. Pharmacists' knowledge of pharmacokinetics and pharmacodynamics and their treatment approach from a global-not fragmented-perspective provides this patient population with broad-based care. In the hospital follow-up of other respiratory diseases, it is already recommended that a pharmacist be a part of the multidisciplinary team [6]. The participation of a pharmacist has been associated with increased quality of life. In the case of asthma, published studies in other countries confirm that pharmacists' interventions achieve more efficient medication use and disease control [7].
The advent of biological therapies in recent years has further increased the complexity of asthma treatment. Of note, in other diseases such as rheumatologic disorders, hospital pharmacists have extensive experience in the monitoring and optimization of medications, since these are classified as medicines for hospital use. In economic terms, use of biologics in severe asthma, as in other diseases, has considerably increased health spending on medicines. Previously, in other medical specialties, the implementation of efficiency strategies by pharmacy departments in coordination with medical departments has considerably reduced hospital costs [8]. We must also take into account the considerable economic impact of inhaled bronchodilators in asthma patients. According to the latest data from the Spanish National Health System, inhaled therapies are at the top of the pharmaceutical budget. $\beta$-adrenergics in combination with corticosteroids occupy the second position in health system expenditure on medicines [9]. In this regard, coordination between hospital pharmacists and community pharmacists can optimize use of and adherence to inhaled therapies in patients with severe asthma in hospital follow-up.

Nevertheless, the participation of hospital pharmacists in multidisciplinary teams for severe asthma in Spain remains unusual. This is surprising, since their involvement could add value to the care of patients with severe asthma. They can also play a key role in the coordination of the medication use process by collaborating with other professionals to achieve more efficient pharmacotherapy. Furthermore, pharmacists can provide information to patients and collaborate in the monitoring and promotion of adherence and ensuring that adherence is adequate. Given that severe asthma is a disease of increasing prevalence that affects chronically ill patients who benefit from increasingly personalized and diverse treatments [10], the incorporation of pharmacists to accredited hospital units could considerably improve health care in this population.

\section{Funding}

The authors declare that no funding was received for the present study.

\section{Conflicts of Interest}

The authors declare that they have no conflicts of interest.

\section{References}

1. The global asthma report. Available at: http://www. globalasthmareport.org/Global\%20Asthma\%20Report\%20 2018.pdf.

2. Quirce S, Delgado J, Entrenas LM, Grande M, Llorente C, López-Viña A, et al. Quality Indicators of Asthma Care Derived 
From the Spanish Guidelines for Asthma Management (GEMA 4.0): A Multidisciplinary Team Report. J Investig Allergol Clin Immunol. 2017;27:69-73.

3. Acreditación de unidades de asma grave SEIAC. Available at: file:///C:/Users/gfaru11/Downloads/checklist_acreditacion_ uag $\% 20$ (1).pdf

4. Cisneros C, Díaz-Campos RM, Marina N, Melero C, Padilla A, Pascual $S$, et al. Accreditation of specialized asthma units for adults in Spain: an applicable experience for the management of difficult-to-control asthma. J Asthma Allergy. 2017;10:163-9.

5. Tan E, Stewart K, Elliot R, George J. Pharmacist services provided in general practice clinics: A systematic review and meta-analysis. Res Social Adm Pharm. 2014;10:608-22.

6. Abraham O, Li JS, Monangai KE, Feathers AM, Weiner D. The pharmacist's role in supporting people living with cystic fibrosis. J Am Pharm Assoc. 2018;58:246-9.

7. Deeks L, Kosari S, Boom K, Peterson G, Maina A, Sharma $R$, Nauton $M$. The role of pharmacists in general practice in asthma management: A pilot study. Pharmacy. 2016;6:114.

8. González-Fernández $M$, Villamañán $E$, Jiménez-Nácher I, Moreno F, Plasencia C, Gaya F, et al. Cost evolution of biological agents for the treatment of spondyloarthritis in a tertiary hospital: influential factors in price. Int J Clin Pharm. 2018;40:1528-38.
9. Annual Report of the National Health System 2018 of Spain. Available at: https://www.mscbs.gob.es/ estadEstudios/estadisticas/sis/nfSanSNS/tablasEstadisticas/ InfAnualSNS2017/7_CAP_17.pdf.

10. Pola-Bibian B, Dominguez-Ortega J, Vilà-Nadal G, Entrala A, González-Cavero L, Barranco P, et al. Asthma exacerbations in a tertiary hospital: clinical features, triggers, and risk factors for hospitalization. J Investig Allergol Clin Immunol. 2017;27:238-45.

Manuscript received December 16, 2019; accepted for publication January 20, 2020.

\section{_ Elena Villamañán}

Pharmacy Department

La Paz University Hospital, IdiPAZ

Paseo de La Castellana 261

28046 Madrid, Spain

E-mail: evillabueno@telefonica.net 